\title{
Analisis Kekuatan Bending dan Tarik Pada Pengelasan 0xy- Acetelyne Menggunakan Garam Kuning
}

\section{Analysis of Bending and Tensile Strengths in Oxy-Acetylene Welding Using Yellow Salt}

\author{
Chendri Johan ${ }^{1 *}$, Frans R. Bethony ${ }^{2}$ \\ 12 Jurusan Teknik Mesin, Fakultas Teknik, Universitas Kristen Indonesia Toraja \\ Diterima: 20-01-2021 ; Disetujui: 17-02-2021 ; Diterbitkan: 06-05-2021 \\ *Corresponding author: chendrijohan@ukitoraja.co.id
}

\begin{abstract}
Abstrak
Meningkatnya ilmu pengetahuan dan dunia industri tidak terlepas dari pemanfaatan teknologi pengelasan. Berdasarkan fakta yang ada, ditemukan keluhan-keluhan pada hasil dari proses pengelasan, seperti kurang kokohnya produk, mudah patah dan crack. Pada umumnya, hal ini disebabkan oleh pengetahuan para welder hanya memiliki keterampilan dalam pengelasan, tetapi tidak memahami faktor-faktor yang berpengaruh terhadap proses pengelasan tersebut. Penelitian ini bertujuan untuk mengetahui sifat mekanis pada pengelasan oxy-acetylene menggunakan garam kuning sebagai flux. Penelitian ini menggunakan metode eksperimental dengan melakukan penelitian secara langsung menggunakan mesin las oxy-acetylene pada proses penyambungan. Pengujian kekuatan hasil sambungan las menggunakan alat uji bending dan uji tarik. Hasil pengujian proses pengelasan oxy-acetylene pada plat aluminium AA 1100 menunjukan bahwa kekuatan tarik rata-rata pada penggunaan garam kuning adalah 71,39 Mpa dengan kekuatan bending rata-rata spesimen 58.98 MPa. Berdasarkan hasil pengujian menunjukkan bahwa pemanfaatan garam kuning sebagai fluks pada proses pengelasan oxy acetylene dapat diterapkan.
\end{abstract}

Kata Kunci: garam kuning, uji tarik, uji bending, AA 1100, flux

\begin{abstract}
Increasing science and the world of industry cannot be separated from the use of welding technology. Based on the existing facts, complaints were found on the results of the welding process, such as the lack of strength of the product, easy fractures and cracks. In general, this is due to the knowledge that the welder only has skills in welding, but does not understand the factors that affect the welding process. This study aims to determine the mechanical properties of oxyacetylene welding using yellow salt as a flux. This study used an experimental method by conducting direct research using an oxy-acetylene welding machine in the connection process. Testing the strength of the welded joints using a bending test and tensile test. The test results of the oxy-acetylene welding process on the AA 1100 aluminum plate showed that the average tensile strength in the use of yellow salt was $71.39 \mathrm{MPa}$ with an average bending strength of the specimen of $58.98 \mathrm{MPa}$. Based on the test results, it shows that the use of yellow salt as a flux in the oxy acetylene welding process can be applied.

Keyword: yellow salt, tensile test, bending test, AA 1100, flux
\end{abstract}

How to Cite: Johan, C., 2021. Analisis Kekuatan Bending dan Tarik Pada Pengelasan Oxy-Acetelyne Menggunakan Garam Kuning. JMEMME (Journal of Mechanical Engineering, Manufactures, Materials and Energy). 5 (1): 48-56 


\section{Chendri Johan, Analisis Kekuatan Bending dan Tarik Pada Pengelasan ...}

\section{PENDAHULUAN}

Kemajuan Industri adalah dampak dari meningkatnya ilmu pengetahuan dan teknologi. Salah satu teknologi yang tidak terlepas dari dunia Industri ialah teknologi pengelasan. Kualitas pengelasan sangat ditentukan oleh beberapa faktor, antara lain: bahan logam yang disambung, jenis elektroda yang digunakan, pengaruh panas, jenis kampuh yang tepat serta posisi saat mengelas [1]. Pengelasan merupakan salah satu cara/metode penyambungan yang digunakan pada konstruksi baja dan konstruksi mesin dimana pada proses ini terjadi penyambungan antara dua material logam. Selain metode ini terdapat beberapa metode penyambungan yang juga digunakan, antara lain: sambungan paku keling dan baut-mur. Teknik pengelasan untuk konstruksi memiliki ruang lingkup yang cukup luas, antara lain: bejana tekan, pipa saluran, jembatan, perkapalan rangka baja, sarana transportasi, rel, dan lain sebagainya [2, 3].

Aluminium memiliki sifat-sifat yang menguntungkan seperti tahan terhadap korosi, konduktor panas dan listrik yang cukup baik serta ringan. Aluminium merupakan nonferrous metal yang memiliki sifat yang kurang baik dalam hal pengelasan [4]. Untuk mendapatkan peningkatan kekuatan mekanik, biasanya logam aluminium dipadukan dengan dengan unsur $\mathrm{Zn}, \mathrm{Mn}, \mathrm{Ni}, \mathrm{Cu}, \mathrm{Si}, \mathrm{Mg}$, dan unsur lain [5]. Aluminium dapat mengalami penurunan ketangguhan, perubahan dimensi, penurunan kekuatan, serta perubahan ketahanan terhadap korosi $[6,7]$.

Dalam pengelasan, penyerapan oksigen sangat tidak dikehendaki sebab akan menimbulkan oksida logam yang memiliki efek jelek terhadap hasil lasan. Untuk itulah dibutuhkan suatu bahan yang dapat melindungi cairan logam dari pengaruh oksidasi, yang disebut dengan flux. Flux selama proses pembakaran akan bereaksi dengan oksida dan melepaskan gas-gas yang timbul serta menghilangkan bahan-bahan yang bukan logam[ ].

Pengelasan merupakan salah satu teknik penyambungan logam dimana dengan mencairkan sebagian logam induk dan logam pengisi dengan atau tanpa tekanan [8]. Definisi pengelasan menurut DIN (Deutsche Industrie Norman) adalah sambungan logam atau logam paduan yang dilaksanakan dalam keadaan lumer atau cair. Dengan kata lain, las merupakan ikatan metalurgi pada sambungan setempat dari beberapa batang logam dengan menggunakan energi panas [4]. 
Proses las oxy-acetylene dalam penyambungan aluminium dapat mempengaruhi daerah lasan yang berbeda terhadap logam induk dan susunan struktur mikro terutama daerah HAZ (Heat Affected Zone). Pada daerah ini terjadi perubahan pada susunan struktur mikro akibat siklus termal yang terjadi saat proses pengelasan. Pemilihan filler juga harus sesuai dengan material dasar (parent material) untuk mencegah hal-hal yang tidak diinginkan seperti retak tegangan, pertumbuhan Kristal dan sebagainya [9]. Pengelasan oxy acetylene masih banyak digunakan di bengkel-bengkel kecil untuk proses repair karoseri mobil, kenalpot mobil dan motor yang menggunakan suhu $3000^{\circ} \mathrm{C}$ yang tidak bisa dilakukan dengan proses lain $[10,11]$.

Gas Asetilin memiliki kelebihan dapat menghasilkan temperatur nyala api lebih tinggi dari gas bahan bakar lainnya, baik dicampur dengan udara maupun oksigen $[4,12]$. Las Oxy-Acetylene menggunakan campuran oxygen dan bahan bakar gas untuk membuat api sebagai sumber panas untuk mencairkan benda keras. Gas dan oxygen dicampur dalam suatu alat dengan komposisi tertentu sehingga api yang dihasilkan bisa mencapai suhu maksimum. Api tersebut berada pada moncong alat pembakaran sehingga dapat diarahkan secara efektif ke arah bagian benda kerja yang akan disambung. Hanya sebagian kecil (bagian ujung) benda kerja yang mencair dan menyatu sehingga setelah membeku membuat suatu sambungan yang kuat yang bisa menyamai kekuatan benda tersebut. Gambaran proses pengelasan tersebut diperlihatkan pada gambar $1[13,14]$.

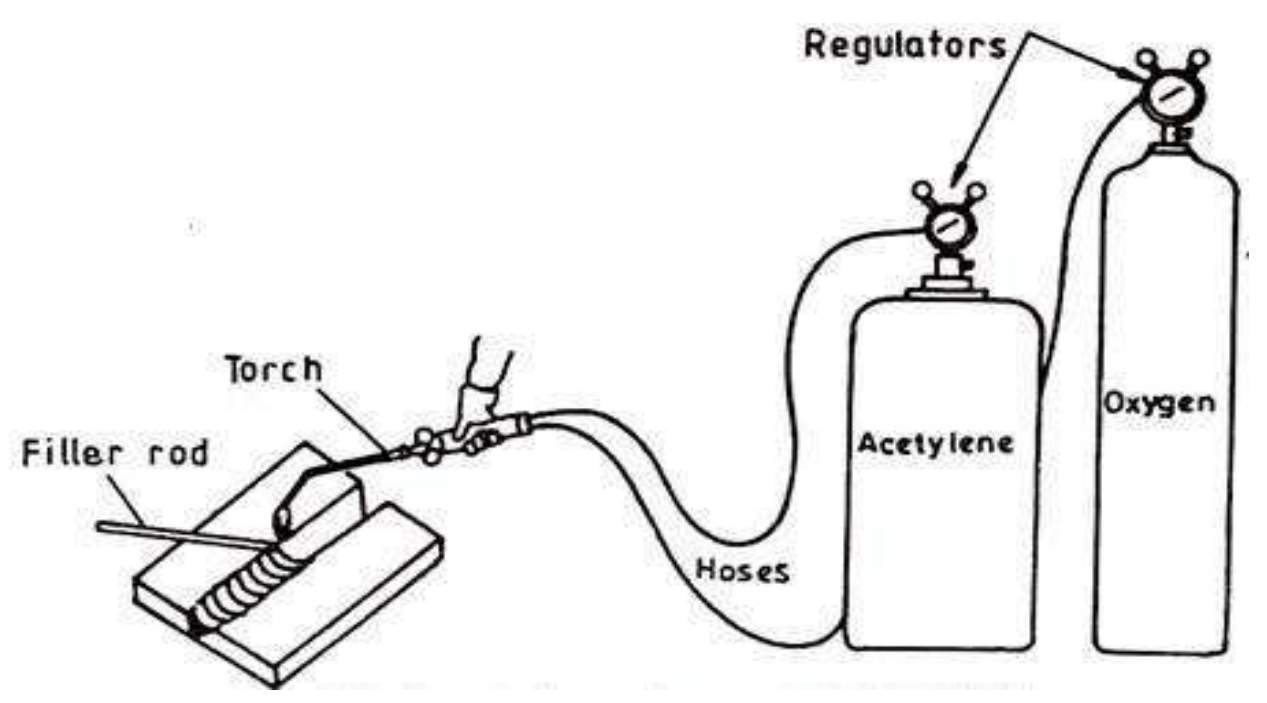

Gambar 1. Gambaran proses pengelasan OAW (oxy acetylene welding)

Garam kuning atau Bleng (natrium biborat, natrium piroborat, natrium tetraborat) adalah campuran garam mineral konsentrasi tinggi dengan bentuk fisik panjang dan 
berwarna agak kuning. Zat ini adalah bentuk tidak murni dari asam borat, sementara bentuk murninya banyak dikenal dengan nama boraks. Di Indonesia, bleng sudah diproduksi sejak tahun 1700 dalam bentuk air bleng. Cairan ini biasanya dihasilkan dari ladang garam atau kawah lumpur. Boraks maupun bleng tidak aman untuk dikonsumsi sebagai makanan, tetapi ironisnya penggunaan boraks sebagai komponen dalam makanan sudah meluas di Indonesia. Mengkonsumsi makanan yang mengandung boraks memang tidak serta berakibat buruk terhadap kesehatan tetapi boraks akan menumpuk sedikit demi sedikit karena diserap dalam tubuh konsumen secara kumulatif. Seringnya mengonsumsi makanan berboraks akan menyebabkan gangguan otak, ginjal dan hati. Bila dalam jumlah banyak borak dapat menyebabkan anuriam deman, merangsang sistem saraf pusat apatis, sianosis, pingsan hingga kematian. Bentuk garam kuning diperlihatkan pada gambar 2 .

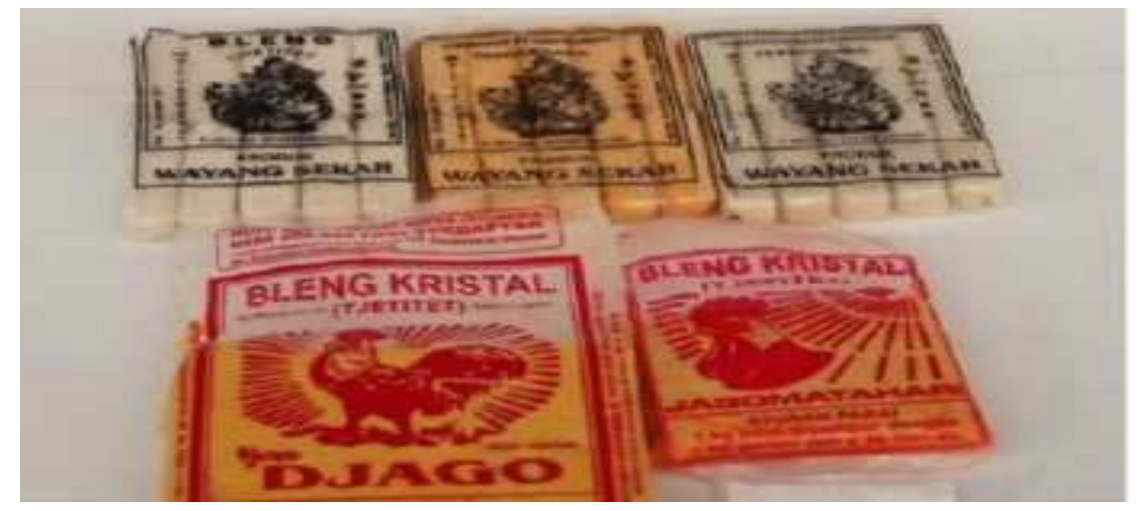

Gambar 2. Garam kuning / bleng

Tujuan penelitian ini ialah untuk mendapatkan beban bending maksimum rata-rata dan kekuatan tarik pada sambungan las Aluminium dengan menggunakan gas oxy asetelin terhadap material plat AA 1100.

\section{METODE PENELITIAN}

Penelitian ini menggunakan metode eksperimental dengan melakukan penelitian secara langsung menggunakan mesin las oxy-acetylene pada proses penyambungan logam. Pengujian kekuatan sambungan hasil lasan menggunakan alat uji bending dan uji tarik. 


\section{Rancangan pengelasan}

Bentuk dan ukuran spesimen uji bending dan tarik secara berturut-turut diperlihatkan pada gambar 3 dan 4.

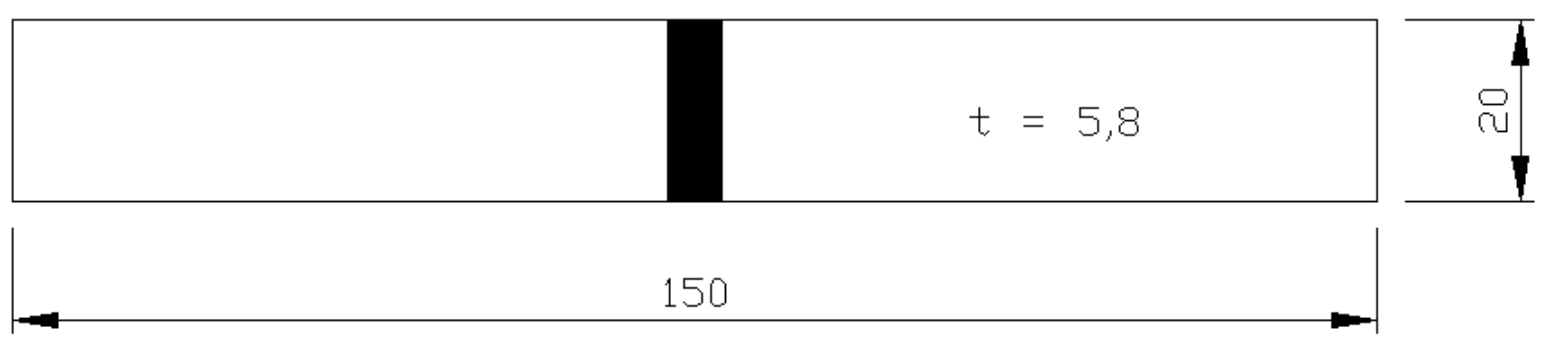

Gambar 3. Spesimen uji bending

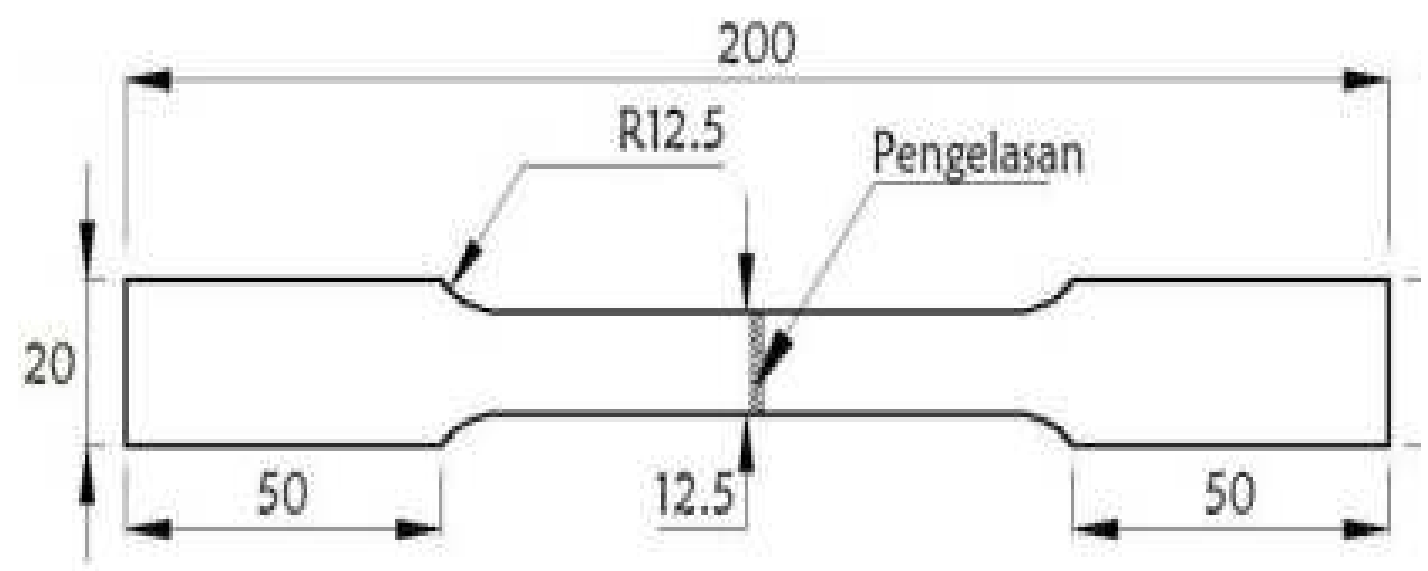

Gambar 4. Spesimen uji tarik mengacu standard ASTM A-370

Gambar 3 dan 4 menunjukkan rancangan spesimen penelitian sebelum dilakukan pengelasan dengan ukuran untuk bending tebal plat 5,8 $\mathrm{mm}$, lebar $20 \mathrm{~mm}$ dan panjang $150 \mathrm{~mm}$ sedangkan pada spesimen uji tarik tebal plat 5,8 $\mathrm{mm}$, lebar $20 \mathrm{~mm}$ dan panjang $200 \mathrm{~mm}$. Setelah benda kerja dibentuk selanjutnya dilakukan pengelasan OAW menggunakan filler dari limbah sepatu rem tromol.

\section{HASIL DAN PEMBAHASAN}

Data yang diperoleh dari pengujian raw material diperlihatkan pada tabel 1, dan pengujian setelah proses pengelasan ditunjukan pada tabel 2 untuk uji tarik dan tabel 3 untuk uji bending. 


\section{Chendri Johan, Analisis Kekuatan Bending dan Tarik Pada Pengelasan ...}

Tabel 1. Hasil uji raw material tarik dan bending

\begin{tabular}{ccccc}
\hline \multirow{2}{*}{ Spesimen } & \multicolumn{2}{c}{ Uji Tarik } & \multicolumn{2}{c}{ Uji Bending } \\
& $\begin{array}{c}\boldsymbol{\sigma} \\
\text { (Mpa) }\end{array}$ & $\begin{array}{c}\boldsymbol{\varepsilon} \\
\mathbf{( \% )}\end{array}$ & $\begin{array}{c}\mathbf{P}_{\max } \\
\text { (kgf) }\end{array}$ & $\begin{array}{c}\mathbf{Y}_{\text {max }} \\
(\mathbf{m m})\end{array}$ \\
\hline Normal & 94.73 & 3.71 & 25.44 & 32.12 \\
\hline
\end{tabular}

Tabel 2. Hasil pengujian tarik pengelasan aluminium AA1100 dengan fluks garam kuning

\begin{tabular}{cccccc}
\hline Spesimen & $\begin{array}{c}\boldsymbol{\sigma} \\
(\mathbf{M P a})\end{array}$ & $\begin{array}{c}\mathbf{L} \\
(\mathbf{m m})\end{array}$ & $\begin{array}{c}\mathbf{b} \\
\mathbf{( m m})\end{array}$ & $\begin{array}{c}\mathbf{t} \\
(\mathbf{m m})\end{array}$ & $\boldsymbol{\varepsilon} \mathbf{( \% )}$ \\
\hline $\mathbf{1}$ & 68.45 & 130 & 5.8 & 20 & 3.71 \\
$\mathbf{2}$ & 70.61 & 130 & 5.8 & 20 & 3.18 \\
$\mathbf{3}$ & 72.77 & 130 & 5.8 & 20 & 3.21 \\
$\mathbf{4}$ & 69.14 & 130 & 5.8 & 20 & 3.25 \\
$\mathbf{5}$ & 72.18 & 130 & 5.8 & 20 & 3.19 \\
Nilai rata-rata & 71.39 & 130 & 5.8 & 20 & 3.33 \\
\hline
\end{tabular}

Tabel 3 Hasil pengujian bending pengelasan aluminium AA110 dengan fluks garam kuning

\begin{tabular}{ccccc}
\hline Spesimen & $\begin{array}{c}\text { Uji Bending } \\
\text { (Kgf) }\end{array}$ & $\begin{array}{c}\mathbf{L} \\
\mathbf{( m m})\end{array}$ & $\begin{array}{c}\mathbf{b} \\
\mathbf{( m m )}\end{array}$ & $\begin{array}{c}\mathbf{t} \\
\mathbf{( m m})\end{array}$ \\
\hline $\mathbf{1}$ & 59.01 & 130 & 5.8 & 20 \\
$\mathbf{2}$ & 58.98 & 130 & 5.8 & 20 \\
$\mathbf{3}$ & 58.92 & 130 & 5.8 & 20 \\
$\mathbf{4}$ & 58.92 & 130 & 5.8 & 20 \\
$\mathbf{5}$ & 59.05 & 130 & 5.8 & 20 \\
Nilai rata-rata & 58.98 & 130 & 5.8 & 20 \\
\hline
\end{tabular}

Pengujian tarik diberi beban secara kontinu hingga perlahan bertambah besar, bersamaan dengan bertambahnya beban maka dilakukan pengamatan terhadap perpanjangan yang dialami benda uji dan dihasilkan kurva tegangan regangan [15]. Patahan spesimen uji tarik pada pengelasan oxy asetelin diperlihatkan pada gambar 5 . 


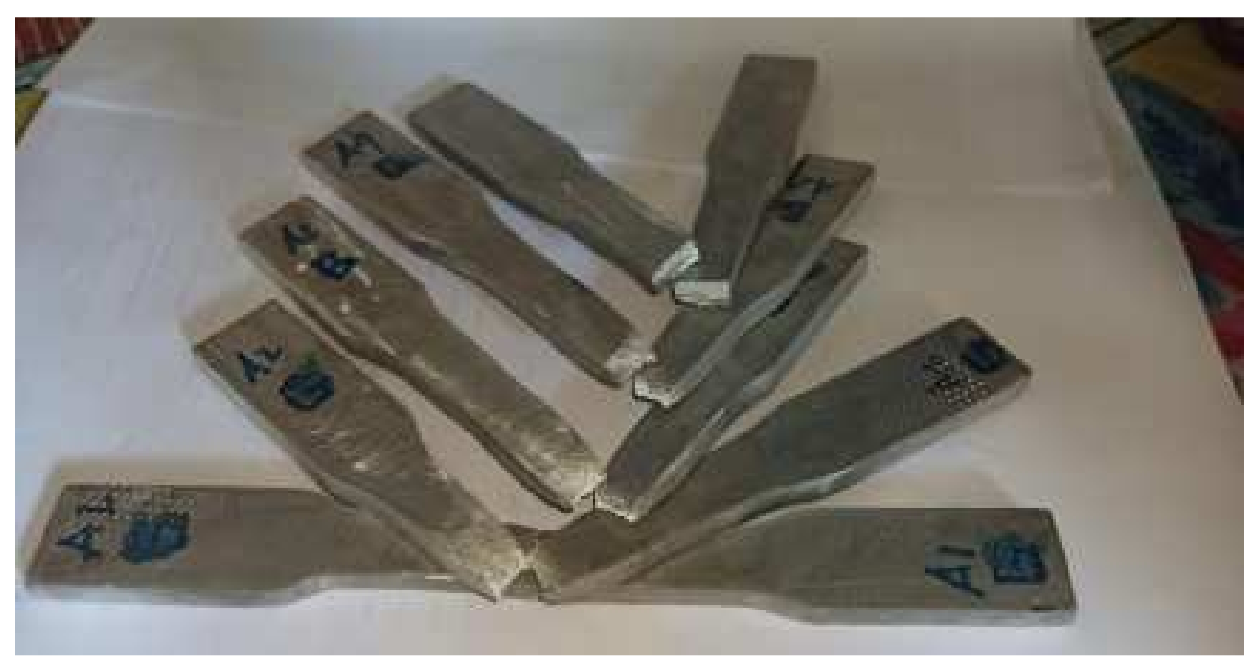

Gambar 5. Patahan spesimen setelah uji tarik

Dari data tabel 2 menunjukkan bahwa nilai kekuatan uji tarik pada pengelasan oxyaxetelin memiliki kekuatan uji tarik rata-rata 71,39 MPa. Grafik hubungan tegangan regangan hasil uji tarik tersebut diperlihatkan pada gambar 6.

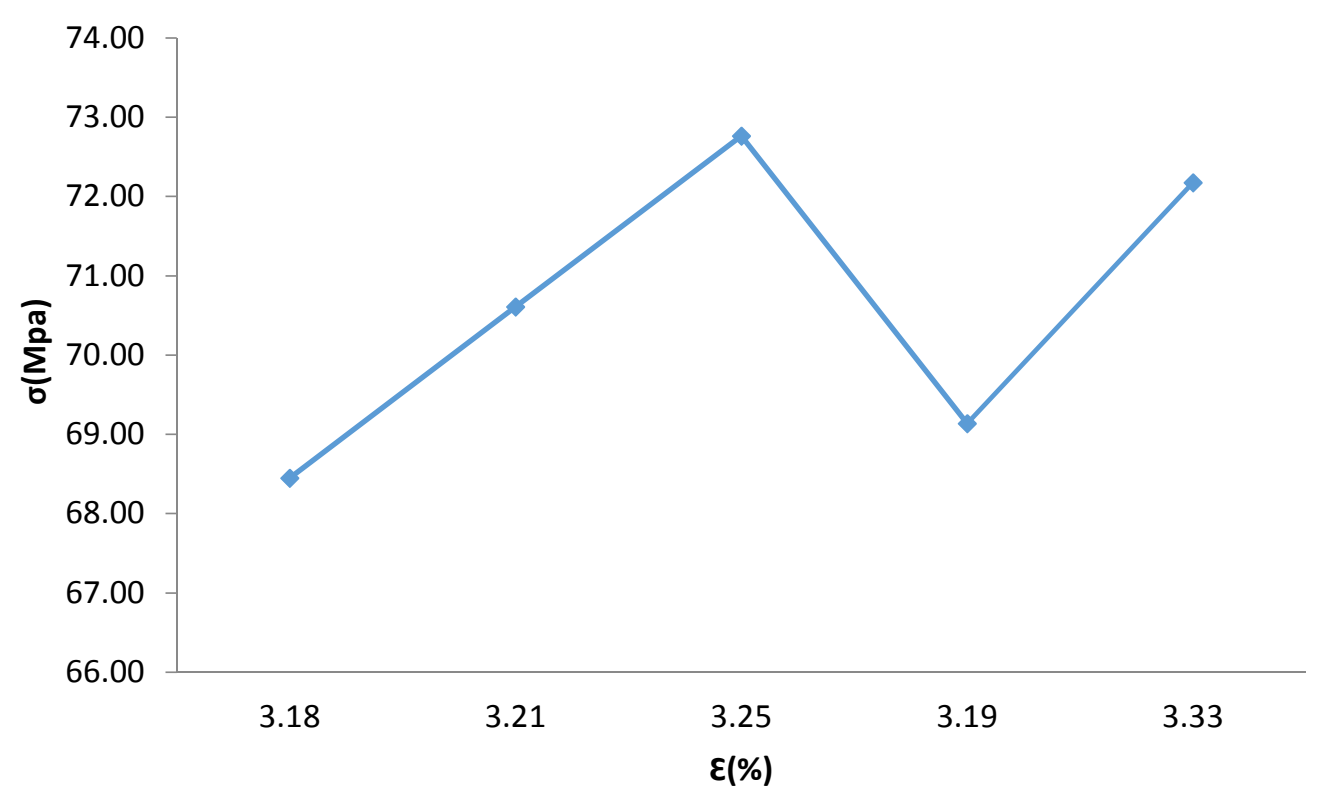

Gambar 6. Grafik tegangan vs regangan hasil uji tarik

Spesimen hasil pengujian bending dari pengelasan oxy asetelin diperlihatkan pada gambar 7. Pada tabel 3 menunjukan bahwa nilai beban bending pada pengelasan oxiasetelin aluminium AA 1100 nilainya meningkat dari uji normal. Dimana untuk raw material pada uji bending ialah sebesar 25,44 kgf. Hasil pengujian uji bending pada pengelasan menggunakan garam kuning dengan 5 spesimen menunjukan nilai rata-rata beban bending pada penggunaan garam kuning sebagai fluks ialah 58,98 kgf. 


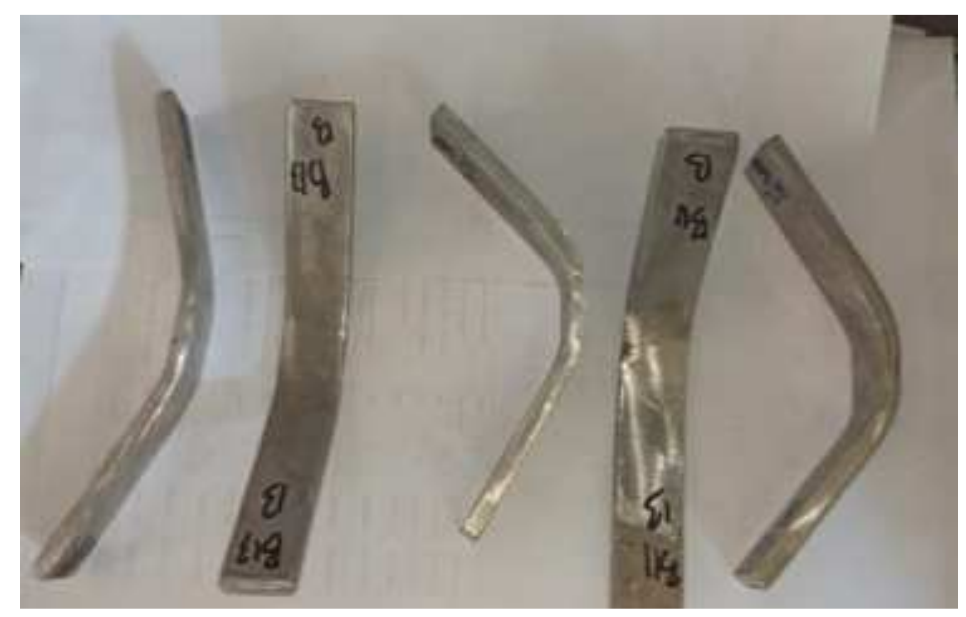

Gambar 7. Spesimen hasil pengujian bending

Dari data yang diperoleh dapat dilihat bahwa pengelasan oxy asetelin menggunakan garam kuning sebagai fluks berpengaruh terhadap nilai kekuatan tarik dan bending. Hal ini dapat dilihat dari data tabel 2 dan tabel 3 yang menunjukkan bahwa terjadi perubahan nilai kekuatan tarik maupun bending dari hasil pengujian raw material. Pengaruh penggunaan garam kuning pada pengelasan oxy asetelin menggunakan filler limbah sepatu rem tromol terhadap nilai beban bending menunjukkan peningkatan dengan beban lentur 58.98 kgf dari 25,44 kgf uji raw material namum terjadi pernurunan nilai pada kekuatan tarik hasil pengelasan yaitu $71.39 \mathrm{MPa}$ dengan regangan $33.3 \%$ dari 94.73 MPa dengan regangan 32,12 \%.

Berdasatkan hasil uji bending, tidak ditemukan keretakan pada hasil pengelasan oxy asetelin seperti ditunjukan pada gambar 7. Hasil pengelasan material setelah terjadi pemanasan menunjukan beban lentur lebih besar dibanding raw material. Pada uji bending yang tidak mengalami pemanasan mempunyai nilai beban lentur kecil. Hal ini terjadi pada pengelasan las oxy asetelin menggunakan fluks garam kuning yang mana fluks ini berfungsi untuk menstabilkan nyala busur dan spatter serta meningkatkan efisiensi pengendapan.

\section{KESIMPULAN}

Berdasarkan hasil pengujian didapatkan bahwa nilai beban bending rata-rata sambungan las aluminium oxy-acetylene terhadap material plat aluminium AA1100 menggunakan garam kuning menunjukkan beban bending adalah 58.98 kgf dan hasil pengujian kekuatan tarik rata-rata sambungan las aluminium oxy asetelin terhadap 
material plat AA 1100 menunjukkan nilai kekuatan tarik rata-rata pada penggunaan garam kuning adalah 71,39 Mpa.

\section{UCAPAN TERIMA KASIH}

Terima kasih kepada kepala laboratorium dan staf Teknik Mesin UKI Toraja dan Teknik Mesin UKI Paulus Makassar, yang telah mendukung penelitian ini sehingga dapat selesai dan dipublish disalah satu jurnal terbaik di Indonesia. Semoga JMEMME (Journal of Mechanical Engineering, Manufactures, Materials and Energy) kedepannya semakin baik.

\section{REFERENSI}

[1] Daryanto, Teknik Las, Bandung: Alfabeta, 2012 .

[2] Saad, Pengaruh Pengelasan SMAW, Semarang: Universitas Negeri Semarang Press, 2008.

[3] A. J. Zulfikar, "The Flexural Strength of Artificial Laminate Composite Boards made from Banana Stems," Budapest International Research in Exact Sciences (BirEx) Journal, vol. 2, no. 3, pp. 334340, 2020.

[4] H. Wiryosumarto and O. Toshi, Teknologi Pengelasan Logam, Jakarta: Pradnya Paramita, 1991.

[5] T. Surdia, Pengetahuan Bahan Teknik, Jakarta: Pradnya Paramita, 1987.

[6] G. E, G. M and K. G.S, "Aluminium alloys as structural material: A review of research," Engineering Structures, vol. 227, no. 1, pp. 13-37, 2021.

[7] M. Y. Yuhazri, A. J. Zulfikar and A. Ginting, "Fiber Reinforced Polymer Composite as a Strengthening of Concrete Structures: A Review," in 2nd International Conference in Industry and Manufacture Engineerin, Medan, 2020.

[8] H. Sonawan and R. Sutratman, Pengantar Untuk Memahami Pengelasan Logam, Bandung: Alfabeta, 2006.

[9] Sriwidharto, Petunjuk Kerja Las, Jakarta: Pradnya Paramita, 2009.

[10] N. Handar and P. Yudi, "Studi Kekuatan Las Oxy Acetylene pada Variasi Kampuh," Jurnal Teknik Mesin, vol. 1, no. 1, pp. 1-8, 2011.

[11] A. J. Zulfikar, A. Sofyan and M. Y. Siahaan, "Numerical Simulation on The Onion Dryer Frame Capacity of $5 \mathrm{~kg}$ /hour," JMEMME (Journal of Mechanical Engineering Manufactures Materials and Energy), vol. 2, no. 2, p. 86-92, 2018.

[12] A. Rahmansyah and A. J. Zulfikar, "Manufacture of Water Pipe From Clampshell Powder Materials," JMEMME (Journal of Mechanical Engineering Manufactures Materials and Energy), vol. 2, no. 2, pp. 73-77, 2018.

[13] F. Hazledine, "Oxy-Acetylene Welding," in Proceedings of the Institution of Mechanical Engineers, New York, 2001.

[14] A. J. Zulfikar, B. Umroh and M. Y. Siahaan, "Design and manufacture of skateboard from banana stem," JMEMME (Journal of Mechanical Enggineering, Manufactures, Materials and Energy), vol. 3, no. 2, pp. 109-116, 2019.

[15] A. Wisnujati, "Analisis Perlakuan Carburizing terhadap Sifat Fisik dan Mekanik pada Bahan Sprocket Sepeda Motor," Jurnal Simetris, vol. 2, no. 1, pp. 22-35, 2017. 